\title{
REVISIÓN DE TÉCNICAS DE SISTEMAS DE VISIÓN ARTIFICIAL PARA LA INSPECCIÓN DE PROCESOS DE SOLDADURA TIPO GMAW
}

\section{STUDY ON THE ARTIFICIAL VISION SYSTEMS TECHNIQUES FOR INSPECTION OF GMAW WELDING PROCESSES}

\author{
MSc. Erik Donaldo Lambraño García*, MSc. José Luis Lázaro Plata* \\ Eng. Alfredo Emilio Trigos Quintero*
}

*Universidad Francisco de Paula Santader. Facultad de Ingenierías, Grupo de Investigación GYTYD. Ocaña, Norte de Santander, Colombia. Teléfono (+57)(7)5690088, E-mail: edlambranog@ufpso.edu.co

*Universidad Francisco de Paula Santader. Facultad de Ingenierías, Grupo de Investigación INGAP. Ocaña, Norte de Santander, Colombia. Teléfono (+57)(7)5690088, E-mail: jllazarop@ufpso.edu.co

*Universidad Francisco de Paula Santader. Facultad de Ingenierías, Grupo de Investigación INGAP. Ocaña, Norte de Santander, Colombia. Teléfono (+57)(7)5690088, E-mail: aetrigosq@ufpso.edu.co

Resumen: El proceso de soldadura GMAW es ampliamente estudiado debido a su alta productividad y bajo costo. En este trabajo se han revisado las investigaciones orientadas a la inspección del proceso de GMAW a través de sistemas de visión artificial con el objetivo de establecer los principales elementos utilizados en estos sistemas destacando dos categorías: métodos computacionales (software y algoritmos generales), materiales y modelos matemáticos (métodos estadísticos y numéricos). Estas categorías se traslapan en el estudio y se han utilizado para evaluar el costo en términos de recursos humanos y recursos económicos. Las investigaciones revisadas se desarrollaron en la última década, con la excepción de algunas investigaciones que desempeñaron un papel principal en el desarrollo de los sistemas de inspección de los procesos GMAW. Finalmente, se han destacado los posibles campos de investigación para aquellos que intentan explorar sistemas de visión artificial para inspección de procesos GMAW.

Palabras clave: GMAW, soldadura, visión artificial, inspección.

\begin{abstract}
The GMAW welding process is widely studied due to its high productivity and low cost. In this paper we have reviewed the research oriented to the inspection of the GMAW process through artificial vision systems to classify them and establish the main elements used in these systems highlighting three categories: technology (hardware), computational methods (software and general algorithms) And mathematical models (statistical and numerical methods). These categories overlap in the document and have been used to assess the cost in terms of human resources and economic resources. The reviewed research was developed over the last decade, with the exception of some research that played a major role in the development of GMAW process inspection systems. Finally, potential research fields for those attempting to explore artificial visual systems for inspection of GMAW processes have been highlighted.
\end{abstract}

Keywords: GMAW, welding, artificial vision, inspection. 


\section{INTRODUCCIÓN}

Gas Metal Arc Welding is a very complex process which uses many engineering and scientific disciplines in order to study techniques which may lead to the best possible mechanical properties of the resulting piece. GMAW process is widely used because of its low cost and productivity if comparing with GTAW (gas tungsten arc welding) and other processes. In spite of these advantages, the fume and spatters produced in the process due to the liquid metal transfer complicate the process (Wang, et. al, 2016), requiring high accurate inspection in order to achieve the mechanical and physical properties needed in industry tasks. In consequence the monitoring systems required for the inspection of GMAW processes have evolved because the human eye cannot detect imperfections due to different variations in the principal parameters involved in the process. For this reason, artificial vision is used in almost every monitoring system for inspection of GMAW processes.

The principal purpose of this work is to provide a constructive analysis of the researches in some of the principal techniques involving artificial vision, its properties, goals, benefits, disadvantages, weaknesses, costs and finally relate and classify them in terms of the usability, accurate inferences about the state of different parameters and measures of the geometric variables of the weld bead in the last fifteen years, as well as to determine and classify the mathematical models used to evaluate the image data obtained in inspection process. This work will help to choose the direction of the artificial vision research through the identification of the topics where the techniques have not gone forward, recommending new research areas.

\section{PROBLEM STATEMENT}

The artificial vision is a non-destructive testing method for visual inspection in GMAW welding process in order to detect faults, irregularities and external defects, such as grooves, incomplete fill groove, misalignment or partial penetration (Dávila, López, Méndez, Osorio and Lefranc, 2016). Inspection can be done registering a welding process picture by picture, but this is not a simple technique; it is a process involving different technologies, techniques and computational methods to registered image information, such as algorithms to process digital images (Sobel, Canny, Gauss filter) or sophisticated mathematical and statistical models such as Multivariate analysis, Artificial Neural Networks, Taguchi Method (Pinto, Mota and Alfaro, 2016).

The wide range of techniques involved in artificial vision are focused on obtaining visual and sensing information in order to monitor and real-time feedback control of seam tracking, measure geometric parameters such as weld penetration, pool shape and seam forming to infer weld quality features (Áviles, Lopez and Rios, 2015).

\section{COMPUTATIONAL METHODS}

Detection of the geometrical features of the weld bead is one of the principal and more difficult tasks in artificial vision due to some aspects of the GMAW process such as the fumes expelling, lighting produced by the arc and spatters. The light produced by the electric arc does not allow capturing high quality images (Wang, Ma and Zhang, 2011) making difficult the image analysis to measure the parameters of the weld bead.

In order to overcome some of the issues mentioned above, some computational techniques have been developed in recent years: algorithms to transform images into readable pictures making easier to determine geometrical features for prediction of possible weld defects. In the following, some principal and widely used techniques are presented

\subsection{IMAGE ANALYSIS ALGORITHMS}

The principal purpose of image processing is to improve the information stored in an digital image for human interpretation, through the manipulation of the discrete quantities $(x, y)$ which constitutes the object and refers to the intensity values or gray level of the image at that pixel (Gonzalez, Woods and Eddinds, 2004).

In capturing a digital image of a GMAW process, it turns necessary to measure the intensity of the arc and detect the lowest point of this to capture the image; the goal is achieved by capturing and measuring the signals of current and tension of the process through an Ethernet shield and synchronizes the camera shutter with the signal analysis determining the precise moment to take the picture avoiding the intense arc light due to the weld process (Cruz, Torres and Alfaro, 2015). 
Also, in (Duarte, Franco, Chagas, Crisóstomo and Alfaro, 2007) a short circuit monitoring system was designed and implemented in order to avoid the noise present in capturing weld images.

Nevertheless, the synchronization process is not enough to capture high quality images. Once the images are obtained it is necessary to apply filters in order to eliminate the interference caused by the arc light intensity (Wang, 2016; Li, Wang, Xu, and Tan, 2010; Shao, Wang and Zhang, 2011; Guo, Shi, Liang and Wang, 2016).

Additionally, because of the hostile environments found in factories, many types of noise can alter the quality of the acquired images, as well as the workpieces which are cleaned and smoothed for the weld process creating a reflective surface over hiding partially the laser stripe (Huang and Kovacevic, 2012).

This means that despite the effort of avoiding the arc light it is not possible with the actual techniques to take completely clear images free from noise and light blurs or excess, being necessary to use algorithms for image processing.

\subsubsection{GAUSS}

One of the principal tasks in image processing is eliminating errors as a result of the image acquisition process which translates in pixel values different from the real intensities, as mentioned above. These errors are commonly known as noise.

The most commonly used filter is Gauss. The effectiveness of this filter in removing noise from images has been proved widely and it is more effective in smoothing images due to the fact that it is based in human visual perception system. It is usually defined by the equation.

$$
H(x, y)=\frac{1}{\sigma \sqrt{2 \pi}} e^{-\frac{\left(x-\mu_{x}\right)^{2}+\left(y-\mu_{y}\right)^{2}}{2 \sigma^{2}}}
$$

Where $\mu_{x}$ and $\mu_{y}$ are the pixel value of the kernel center, $\sigma$ is the standard deviation $(\mathrm{Li}$, et. al., 2010), and a $5 \times 5$ order kernel, here mu $x$ and mu_y are the pixel value of the kernel.
In (Park, Kim, Lee, Jin and Kim, 2016) the Gauss filter was used to minimize possible measurement errors caused by incidents as explosions in the short-circuit metal transfer mode.

After eliminating noise, an algorithm must be applied to detect the edges of the weld pool. This can be achieved through algorithms such as Sobel, Canny, Roberts, Perwitt and Laplacian. Neverthless, Canny operator produce better results than other algorithms in accuracy and continuity of edge detection (Xu, Fang, Chen, Zou and Ye, 2014).

\subsubsection{SOBEL AND CANNY OPERATORS}

Next step, the Sobel filter is used to measure the intensity gradient of the image to find where the intensity of pixels increase. This is composed by two $3 \times 3$ order convolution kernels:

$$
\left(\begin{array}{lll}
-1 & 0 & 1 \\
-2 & 0 & 1 \\
-1 & 0 & 1
\end{array}\right) \quad\left(\begin{array}{ccc}
1 & 2 & 1 \\
0 & 0 & 0 \\
-1 & -2 & -1
\end{array}\right)
$$

\section{$\mathrm{X}$-direction and $\mathrm{Y}$-direction filters}

the $\mathrm{x}$-direction and the $\mathrm{y}$-direction. These kernels are built to respond to vertical and horizontal edges, one kernel for each perpendicular axe. After applying the Sobel operator the horizontal and vertical lines detected will be highlighted by each of the kernels respectively (Shao, et al., 2011; Muhammad, Altunu and Abo, 2016; Wang, Huang and Zhang, 2013; Xu, fang, Chen and Zou, 2015).

Also, after applying the Gauss filter, the edges of the weld bead can be detected in order to measure the geometrical features of the weld bead and this is achieved through the Canny filter. This edge detector works within a multi stage process requiring the elimination of noise in the imaging and a simple 2D operator used to highlight regions of the image. The input is a gray scale image and the output is an image with the track intensity discontinuities (Shao, et al., 2011; Muhammad, et al., 2016; Wang, et al., 2013; Guo, et al., 2016; $\mathrm{Xu}$, et. al., 2015; Shen, Wu, Lin and Chen, 2008; Gao, Zhong, You and Katayama, 2012).

In (Shao, et al., 2011), after several experiments, excellent results were obtained involving both operators: the Sobel algorithm is used to detect edges in the brighter areas of the image and the Canny operator is used in the darker ones. 
In order to detect the edges of droplet to study the metal transfer, Sobel and Canny operator were used in (Wang, 2016) and it was difficult to distinguish the edges of the droplet. Similar results were obtained with the graph cut-based method Results by gray level co-occurrence matrix based. method showed it is very time consuming, which is a great disadvantage for real-time detection purposes.

As an alternative, a novel method is proposed choosing a Region of Interest (ROI) and applying a band-pass filter formulated as

$$
\begin{aligned}
& \text { W(f_x,f_y })=\left\{\left(\left(f \_x-f \_\{c x\}\right)^{\wedge} 2+\left(f \_y-\right.\right.\right. \\
& \left.\left.f_{-}\{c y\}\right)^{\wedge} 2\right)^{\wedge}\{0.25\} \quad \text { if } \quad f_{-}\{x c l\}<f \_x<f \_\{x c u\} \\
& \text { f_ }\{y c l\}<f \_y<f \_y c u
\end{aligned}
$$$$
W\left(f_{x}, f_{y}\right)=\left(\left(f_{x}-f_{c x}\right)^{2}+\left(f_{y}-f_{c y}\right)^{2}\right)^{0.25}
$$

With the restriction $f_{x c l}<f_{x}<f_{x c u}$ and $f_{y c l}<f_{y}<f_{y c u}$

Or 0 else $f_{x}$

Where $f_{x}, f_{y}$ represent the frequencies, and $f_{x c l}, f_{x c l}$ represent the lower cut off frequency in the $f_{x}$ direction and $f_{y}$ direction respectively.

After the image processing with filter in equation (**) the edge detection is carried out.

Canny algorithm is not as effective as expected when it is used to detect V-grooves in a weld bead due to the fact that judgment conditions must be based on prior knowledge. Also, application to Vgrooves detection often produces false edges resulting in a low accuracy of the image processing. In order to overcome this shortcomings an improved Canny algorithm is proposed in (Guo, et al., 2016), and through this algorithm, possible weld deviation can be detected.

\subsubsection{HOUGH TRANSFORM}

In order to process digital images it is necessary to reduce the amount of data and to preserve the important and structural information. The Hough transform was developed initially to detect and highlight lines and then evolved to recognize arbitrary shapes.
Together with pattern recognition and line fitting, Hough Transform is used to detect feature points of the weld bead or the baseline of the stripes on the surface of the weldment. Li et. al, (2010) used the Hough transform to calculate the bead dimensions. It is also used after applying a segmentation method which identifies the image pixels composing the weld line. The Modified Hough Transform is able to find the coordinates which best represents the weld line (Carvalho, Luciano, Freire, Molina and Freire, 2009). Muhammad et at, (2016) used this transform to detect laser stripes orientation and use it as a reference line. Ranjan, Khan, Parikh, Jain, Mahto and Pal (2016) offer a complete explanation of the application process; here, the Hough transform is used to classify defects on the weld bead into voids, grooves, cracks, flash and key-hole defects.

\subsubsection{FURTHER APPLICATIONS}

\subsubsection{DROPLETS DETECTION}

The solid to liquid metal transfer in GMAW is a complicated process due to the fumes and spatters it expelled during the procedure. Also, the amount of material used in the process determines the time and economical resources, justifying the need to understand and control the metal transfer in order to improve stability, quality and energy consumption.

Some experiments have been developed in [49] to study the analysis of metal transfer by capturing images of the process. Gauss filter was used to reduce noise and an algorithm using a doublethreshold method is proposed for better results. The histogram distribution and the gray-scale was used to calculate the slope difference in order to find both thresholds approximations.

Using double-threshold segmentation method has some advantage in comparison with other threshold methods: the accuracy in processing fuzzy images, easy to handle and the cost of the elements involved.

To study the metal transfer it becomes necessary to study the droplet. This is usually like an ellipsoid and there about two oscillations before it falls on the weld pool. Additionally, approximations of the surface tension and the period of the droplet need to be determined in pursuance of understanding the weld bead formation and control the geometrical features and in consequence the mechanical properties of the weld bead 
Investigation to understand the droplet size, droplet shape and speed of droplet when falling into the plasma are explained and developed in (Chapuis, Romero et al., 2013; Chen et al., 2016). Furthermore, some results are discussed by comparing two different shield gases: pure argon and $\mathrm{CO} 2$.

When capturing images of the metal transfer from high speed videos, the geometry of the droplet is analyzed through edge detection (Chapuis et al., 2013). This allows measuring the surface tension of the droplet by analyzing the oscillations during the free flight. It was demonstrated through metal transfer analysis that higher speed is obtained with argon.

Also, it is possible to use a low power to detach the droplet at a desired size that best suits for the control of the weld pool. This is achieved by edge detection of the droplet in a laser-enhanced GMAW process and this is used to derive the boundary of the droplet, where Sobel and canny operators were used in different parts of the same image as mentioned in last section, in order to obtain better results. (Kiran, et al., 2016)

The image processing methods allows to study, as mentioned, the geometry of the weld bead and the droplet. This information let us infer the amount of material used in the process, wasted material and the mechanical properties of the resulting piece, which is important for industrial purposes.

Also, through detection of the edges of the weld bead is possible to identify defects in GMAW process. This subject has been studied widely (Alfaro, Vargas, De Carvalho and De Souza, 2015; Ali, Gsimalla and Dening, 2013; Chu and Wang, 2016; Gomes, Costa, Paiva and Balestrassi, 2012; Huang and Kovacevic, 2011; Senthil, Natarajan, Veerajan and Ananthan, 2014; Squillace, Prisco, Ciliberto and Astarita, 2012; Wang, Zhang, and $\mathrm{Wu}, 2010)$ and is almost the main purpose in visual inspection of robotic GMAW process.

Weld defects means low quality of the welded structures and risk of part fatigue due to the resulting mechanical properties (Alfaro, et al., 2015). For this reason there are several methods for detecting weld defects.

\subsection{SOFTWARE}

One of the costs that must be included in the budget for visual systems is the software, LabVIEW and MATLAB being the most commonly used. Nevertheless, MATLAB (Rodríguez $\mathrm{O}$ et al., 2012) is on the top for image processing and analysis tasks being used in to detect weld defects (Chokkalingham, et al., 2012; $\mathrm{He}, \mathrm{Xu}, \mathrm{Chen}$ and Chen, 2016; Reisgen et al., 2014; ummenhofer and Medgenberg, 2009) to study the metal transfer through droplet detection and build 3D determining concrete features of the weld profile (Sreedhar, Krishnamurthy, Balasubramanjam, Raghupathy and Ravisankar, 2012; Wang et al., 2010; Ramos et al., 2013; ).

LABVIEW is a graphic-language based software flexible and ease-of-use platform which sometimes is used together with MATLAB.

An algorithm was developed by Sreedhar et al., (2012) in order to process IR thermal data in real time for weld defects detection. In this research, some algorithms for image registration, such as image angle correction, circumferential location and generation of cooling curves, were developed in MATLAB, and then the algorithms were assembled in a single piece as an automatic IR image analysis software using LabVIEW.

This tool has been also used to develop systems for multi-purpose tasks: geometrical features measurement, seam tracking and 3D profiling, processing successfully a complete image in just $3 \mathrm{~ms}$ and a high efficiency and simple programming if a different configuration is required. According to (Reisgen et al, 2014) the most common use of this tool refers to data acquisition and image processing.

This matrix-based language allows expressing computational mathematics. Its high performance language makes possible algorithm development, data analysis, visualization, application development, Graphical User Interface building. 
The MATLAB Image Acquisition and Image Processing toolboxes are used commonly in visual inspection. Additionally, it is used for prediction through Neural Network Toolbox with the transfer, training, learning and performance functions included in the toolbox. It is possible to establish relationships between the welding input parameters (weld speed, voltage, current) through ANN with this tool (Sreeraj, Kannan, \& Maji, 2013; ), as well as trace a 3D profile of the weld bead. In a research developed by (Ramos et. al.,(2013) the signal of the GMAW process were acquired with LabVIEW and the images were processed with MATLAB to determine the oscillation of the weld pool showing that the arc applies some pressure on the pool, oscillating in a regular state.

\section{HARDWARE}

Most of the artificial vision systems for welding inspection, used in research purposes, are very expensive systems due to the high quality of inspection required: an LDI SLP Laser Scanner, a portable 3D laser scanning system with high accuracy, costs from US\$16.900 to US\$22.900. The ViALUX z-Snapper 3D Camera price varies from US\$25.000 to US\$50.000; this is a LEDbased DLP projection 3D camera. While the Surphaser HSX Laser Scanner price ranges from US\$90.000 to US\$150.000 depending on the accessories and post-processing software included. This hardware is known by its speed, unsurpassed accuracy and ease-of-use. The associated software is able to export $3 \mathrm{D}$ datasets with little noise for post processing purposes. However, it is possible to use a cheap visual system for inspection when using the right algorithms and software for research purposes.

A visual system for GMAW inspection was developed by Huang and Kovacevic (2011) with a total cost of US\$2.500 in 2011, where specific features and prices can be found. This includes a license for LabVIEW to develop image processing.

The system developed results efficient for industrial purposes in terms of cost, time cycle and on-line image processing capabilities.

\subsection{D PROFILING TECHNIQUES}

Line Structured Light Vision Sensors (LSLVS) are used in 3D profiling techniques of the weld bead in GMAW process. An LSLVS is constituted by a camera and a light plane projector used to generate a structured light over the weld surface; then, the reflected structured light is captured with a CCD camera (Guo et al., 2010).

\subsection{INFRARED CAMERAS}

Laser illumination and monochromatic imaging is used to measure the weld bead [30] in order to overcome the arc lighting. Other methods used to avoid lighting are infrared cameras (Shengqiang, et al., 2011) and the analysis of thermal images captured through thermovision techniques. An algorithm was developed by (Squillace et al., 2012) to compare radiographic and thermographic data from the weld bead to identify defective weld regions detecting defects automatically.

Infrared thermography consists in capturing the electromagnetic waves in the infrared spectrum in a body at certain specific temperature through the Planck's Law.

Once images are captured it is necessary to reduce the noise present through filters such as Gauss filter (Rios, America, Morales, Aviles, Nas and Lopez-Juarez, 2016)

These methods often are related to image analysis and processing (Ummenhofer \& Medgenberg, 2009) in order to transform the image data into images where the welding process features, such as geometry of the weld bead, can be measured and analyzed.

The technology required in monitoring systems includes different types of cameras, filters, Ethernet shields (Ogawa, 2011). The different models of the apparatus used in each process depends on the space where the process is to be developed, the parameter that is going to be measured, the technique applied and the principal purpose of the research.

\section{MATHEMATICAL MODELS}

Despite the amount of techniques and algorithms built to infer the geometrical features of the weld bead with specific input parameters, there is still a gap in mathematical models to predict bead geometry over a wide range of welding conditions (Park et al., 2016). Nevertheless, there are some models oriented to analyze and predict specific geometrical features, such as width bead or height (Caballero A. et al., 2013). 


\subsection{ARTIFICIAL NEURAL NETWORKS}

Artificial Neural Networks (ANN) are biologically inspired techniques (Sreeraj et al., 2013), which simulates an interconnected parallel computational structure with some individual processing elements. Some areas where ANN are applicable are classification, associative memory, clustering or compression, generation of sequences or patterns and control systems (Cruz et al., 2015). These powerful tools have been used, even to develop smart home control by voice (Camargo, Coronel and Calderón, 2014).

ANN were used in by Campbell, Galloway \& McPherson (2012) to find the most influential input parameter in the geometrical features. In this process two different shielding gases were provided at a given constant frequency. The model used can predict penetration, length and thickness for a given set of weld parameters. It was found that travel speed is the most influential input parameter in predicting the geometry of the weld bead.

Defects on GMAW process can be classified to ampere defects, travel speed and gun defects were used to distinguish welding defects obtaining $80 \%$ success in poor quality weld bead recognition and $90 \%$ success in high quality weld bead, establishing the ability for ANN in classifying weld beads.

Frequently ANN are used together with some other tools due to the fact that ANN has some limitations in predicting processes. According to Akkas, Karayel, Ozkan, Ahmet and Topal (2013) it was possible to model the relationship between the input parameters using ANN and a neurofuzzy approach; Xiong, Zhang, $\mathrm{Hu}$ and $\mathrm{Wu}$ (2014) predicted the weld bead parameters through ANN and a second-order regression analysis in robotic GMAW process, obtaining a better performance with ANN rather than the second-order regression model because of the ability of ANN in approximating nonlinear processes.

Many ANN have been proposed for ANN network algorithms but Back Propagation algorithm is actually considered the best algorithm for prediction task using ANN (Sreeraj, Kannan and Maji, 2013).

\subsection{ANN and Genetic Algorithms}

Genetic Algorithms (GA) techniques, inspired in biological evolution, can be integrated with
ANN (Sreedhar et al., 2012) in order to determine optimal input parameters to get high quality dilution of materials in GMAW process (Baskoro et al., 2009; Kim et al., 2005).

To carry out the analysis of image data and determine the number of experiments some mathematical and statistical models are needed. For example, the Pareto frontiers (Gomes et al., 2012) are used when the effect of many parameters (different aspects of the welding process as productivity, amount of material used, cost, weld bead geometry, mechanical properties of the result) need to be optimized; the Taguchi method and Grey relational analysis (Kiran et al., 2016) have been used to estimate the values of the parameters that optimizes the parameters of the weld bead geometry in TIG welding process. Other statistical models as the Mahalanobis Distance (Shengqiang et al., 2011) have been used to analyze welding faults due to the variation of parameters such as wire feed speed or ampere defects.

\section{CONCLUSIONS}

Artificial Neural Networks and Genetic Algorithm constitute powerful tools to establish inferences about the behavior of the geometrical features of the weld bead when modifying input parameters: voltage, current and speed.

Despite the variety of algorithms and mathematical models built to inspect some of the geometry parameters of the weld bead, none of these are still capable of predicting the bead geometry in different welding conditions.

Inferences about the dependence between different parameters are still to be determined. Sophisticated tools such as ANN allow to infer some of these relations. As an example, the bead width is affected more than the bead height in different welding processes parameters.

A closed loop control system to study droplet features for GMAW metal transferring is required.

High accuracy measurements can be achieved with low cost vision systems using CCD cameras and LSVLS technique. 


\section{ANNEX}

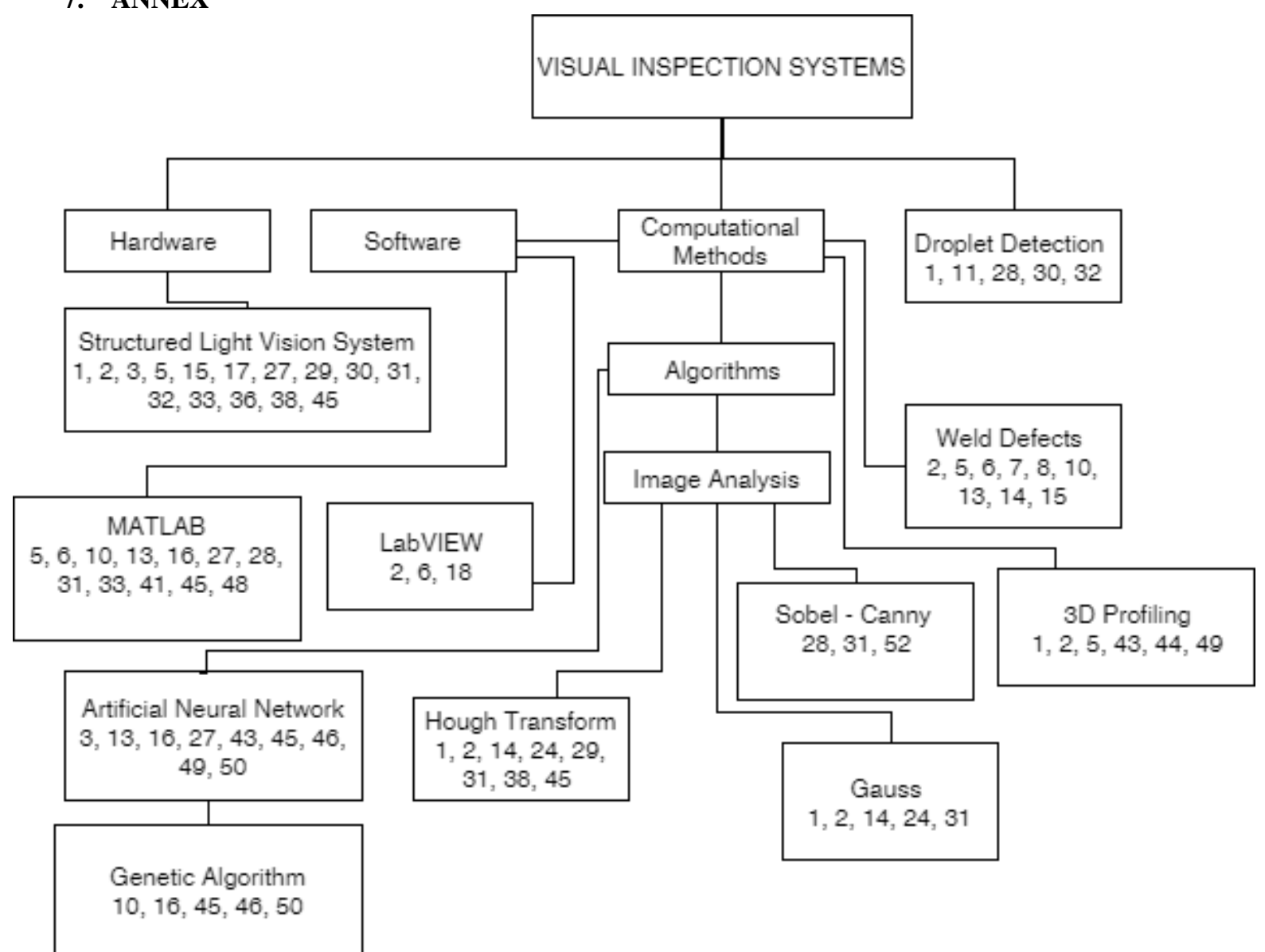

Figure 1. Visual inspection systems.

\section{ACKNOWLEDGMENTS}

We thank the research groups GITYD and INGAP for its support in the development of the present research.

\section{REFERENCES}

Akkas, N., Karayel, D. G., Ozkan, S. S., Ahmet, O. L., \& Topal, B. (2013). Modeling and Analysis of the Weld Bead Geometry in Submerged Arc Welding by Using Adaptive Neurofuzzy Inference System. Mathematical Problems in Engineering, 2013, 1-10. http://doi.org/10.1155/2013/473495

Alfaro, S. C. A., Vargas, J. A. R., De Carvalho, G. C., \& De Souza, G. G. (2015). Characterization of "humping" in the GTA welding process using infrared images. Journal of Materials Processing Technology, 223, 216-224. http://doi.org/10.1016/j.jmatprotec.2015.03.052

Ali, G., Gsimalla, G., \& Dening, J. (2013). Implementation of Welding Defects Detection and Monitoring in Arc Welding Robots.
International Journal of Science and Research (IJSR) ISSN (Online Index Copernicus Value Impact Factor, 14611(2), 2319-7064. Retrieved from www.ijsr.net

Aviles-Viñas, J. F., Lopez-Juarez, I., \& RiosCabrera, R. (2015). Industrial Robot: An International Journal For Authors Acquisition of welding skills in industrial robots. Industrial Robot: An International Journal An International Journal Industrial Robot An International Journal Industrial Robot An International Journal, 42(2), 156-166. Retrieved from http://dx.doi.org/10.1108/IR-09-20140395

Aviles-Viñas, J. F., Rios-Cabrera, R., \& LopezJuarez, I. (2016). On-line learning of welding bead geometry in industrial robots. International Journal of Advanced Manufacturing Technology, 83(1-4), 217-231. http://doi.org/10.1007/s00170-015-7422-6

Baskoro, A. S., Masuda, R., Kabutomori, M., \& Suga, Y. (2009). An application of genetic algorithm for edge detection of molten pool in fixed pipe welding. International Journal of 
Advanced Manufacturing Technology, 45(1112), 1104-1112. http://doi.org/10.1007/s00170009-2048-1.

Caballero Amaury, Velasco Gabriel, Pardo García A. (2013). Differentiations of objects in diffuse databases. Revista colombiana de tecnologías de Avanzada. 2 (22). Pág. 131 - 137.

Camargo, E., Coronel and Calderón, M. (2014). Hogar inteligente por control de voz usando redes neuronales. Revista Colombiana de Tecnologías de Avanzada. Vol 1. Núm. 25.

Campbell S., Galloway, A. M., \& McPherson, N. A. (2012). Artificial Neural Network Prediction of Weld Geometry Performed Using GMAW with Alternating Shielding Gases. Welding Journal, 91(6), 174-181.

Carvalho, E. A. N., Luciano, B. A., Freire, R. C. S., Molina, L., \& Freire, E. O. (2009). Faulttolerant weld line detection for automatic inspection of storage tanks based on distance and visual information fusion. 2009 IEEE Intrumentation and Measurement Technology Conference, I2MTC 2009, (May), 791-796. http://doi.org/10.1109/IMTC.2009.5168558

Chapuis, J., Romero, E., Soulie, F., \& Bordreuil, C. (2013). Experimental Analysis of Droplet-Gas Interaction During Gmaw Process. Trends in Welding Research: Proceedings of the 9Th International Conference, 448-452.

Chen, S., Zhang, S., Huang, N., Zhang, P., \& Han, J. (2016). Droplet transfer in arcing-wire GTAW. Journal of Manufacturing Processes, 23, 149156. http://doi.org/10.1016/j.jmapro.2016.05.014

Chokkalingham, S., Chandrasekhar, N., \& Vasudevan, M. (2012). Predicting the depth of penetration and weld bead width from the infrared thermal image of the weld pool using artificial neural network modeling. Journal of Intelligent Manufacturing. http://doi.org/10.1007/s10845-011-0526-4

Chu, H.-H., \& Wang, Z.-Y. (2016). A vision-based system for post-welding quality measurement and defect detection. International Journal of Advanced Manufacturing Technology, 86(912). http://doi.org/10.1007/s00170-015-8334-1

Cruz, J. G., Torres, E. M., \& Absi Alfaro, S. C. (2015). A methodology for modeling and control of weld bead width in the GMAW process. Journal of the Brazilian Society of Mechanical Sciences and Engineering. http://doi.org/10.1007/s40430-014-0299-8

Dávila-Ríos, I., López-Juárez, I., Méndez, G. M., Osorio-Comparán, R., Lefranc, G., \& Cubillos, C. (2016). A fuzzy approach for on-line error compensation during robotic welding. 2016 6th
International Conference on Computers Communications and Control, ICCCC 2016, (Iccce), 264-270. http://doi.org/10.1109/ICCCC.2016.7496772

Duarte, L., Franco, N., Chagas, C. M., Koike, C., Crisóstomo, S., \& Alfaro, A. (2007). Real time synchronization of weld pool image acquisition in the dip mode of metal transfer GMAW processes, 3-8.

Gao, X., Zhong, X., You, D., \& Katayama, S. (2012). Kalman Filtering Compensated by Radial Basis Function Neural Network for Seam Tracking of Laser Welding. Control Systems Technology, IEEE Transactions on, $\mathrm{PP}(99), 1$. http://doi.org/10.1109/TCST.2012.2219861

Gomes, J. H. F., Costa, S. C., Paiva, A. P., \& Balestrassi, P. P. (2012). Mathematical modeling of weld bead geometry, quality, and productivity for stainless steel claddings deposited by FCAW. Journal of Materials Engineering and Performance.

Gonzalez, R. C. E., Woods, S. L., Gonzalez, R. E. R. E. R. C., Woods, R. E., \& Eddins, S. L. (2004). Digital image processing using MATLAB (No. 04; TA1637, G6.).

Guo, B., Shi, Y., Yu, G., Liang, B., \& Wang, K. (2016). Weld deviation detection based on wide dynamic range vision sensor in MAG welding process. The International Journal of Advanced Manufacturing Technology, 87(9-12), 33973410. http://doi.org/10.1007/s00170-016-87212

Guo, H., Hu, J., \& Tsai, H. L. (2010). ThreeDimensional Modeling of Gas Metal Arc Welding of Aluminum Alloys. Journal of Manufacturing Science and Engineering, 132(2), http://doi.org/10.1115/1.4001479

He, Y., Xu, Y., Chen, Y., Chen, H., \& Chen, S. (2016). Weld seam profile detection and feature point extraction for multi-pass route planning based on visual attention model. Robotics and Computer-Integrated Manufacturing, 37, 251261. http://doi.org/10.1016/j.rcim.2015.04.005

Huang, W., \& Kovacevic, R. (2011). A laser-based vision system for weld quality inspection. Sensors, 11(1), 506-521. http://doi.org/10.3390/s110100506

Huang, W., \& Kovacevic, R. (2012). Development of a real-time laser-based machine vision system to monitor and control welding processes. International Journal of Advanced Manufacturing Technology, 63(1-4), 235-248. http://doi.org/10.1007/s00170-012-3902-0

Kim, I. S., Son, J. S., Park, C. E., Kim, I. J., \& Kim, H. H. (2005). An investigation into an intelligent system for predicting bead geometry 
in GMA welding process. Journal of Materials Processing Technology, 159(1), 113-118. http://doi.org/10.1016/j.jmatprotec.2004.04.415

Kiran, D. V., Cheon, J., Arif, N., Chung, H., \& Na, S. (2016). Three-dimensional finite element modeling of pulsed AC gas metal arc welding process. The International Journal of Advanced Manufacturing Technology, 1, 1453-1474. Li, Y., Li, Y. F., Wang, Q. L., Xu, D., \& Tan, M. (2010). Measurement and defect detection of the weld bead based on online vision inspection. IEEE Transactions on Instrumentation and Measurement, 59(7), 1841-1849. Muhammad, J., Altun, H., \& Abo-Serie, E. (2016). Welding seam profiling techniques based on active vision sensing for intelligent robotic welding. International Journal of Advanced Manufacturing Technology, 1-19. http://doi.org/10.1007/s00170-016-8707-0

Ogawa, Y. (2011). High speed imaging technique Part 1 - high speed imaging of arc welding phenomena. Science and Technology of Welding and Joining, 16(1), 33-43. http://doi.org/10.1179/136217110X1278588954 9903

Park, M. H., Kim, I. S., Lee, J. P., Kim, D. H., Jin, B. J., Kim, I. J., \& Kim, J. S. (2016). Sensitivity Analysis for Prediction of Bead Geometry using Plasma Arc Welding in Bellows Segment. International Journal of Engineering Research \& Science, 2(4), 2395-6992.

Pinto-Lopera, J. E., Motta, J. M. S. T., \& Alfaro, S. C. A. (2016). Real-time measurement of width and height of weld beads in GMAW processes. Sensors (Switzerland), 16(9), 1-14. http://doi.org/10.3390/s16091500

Ramos, E. G., de Carvalho, G. C., \& Absi Alfaro, S. C. (2013). Analysis of weld pool oscillation in P-GMAW by Means of Shadowgraphy Image Processing. Soldagem \& Inspecao, 18(1), 39$49 . \quad$ http://doi.org/10.1590/S010492242013000100006

Ranjan, R., Khan, A. R., Parikh, C., Jain, R., Mahto, R. P., Pal, S., ... Chakravarty, D. (2016). Classification and identification of surface defects in friction stir welding: An image processing approach. Journal of Manufacturing Processes, 22, 237-253. http://doi.org/10.1016/j.jmapro.2016.03.009

Rodríguez Oscar Oswaldo, Pineda Pinto Ronald Fernando, Cárdenas Pedro Fabián. (2012). Herramientas EJS 3D/MATLAB para el control del sistema no lineal aplicado al péndulo invertido sobre carro deslizante. Revista colombiana de tecnologías de Avanzada. 1 (19). Pág. $28-34$.
Reisgen, U., Purrio, M., Buchholz, G., \& Willms, K. (2014). Machine vision system for online weld pool observation of gas metal arc welding processes. Welding in the World, 58(5), 707711. http://doi.org/10.1007/s40194-014-0152-9

Rios-Cabrera, R., America, ·, Morales-Diaz, B., Aviles-V Nas, J. F., \& Lopez-Juarez, I. (2016). Robotic GMAW online learning: issues and experiments. Int $\mathrm{J}$ Adv Manuf Technol, 87, 2113-2134. http://doi.org/10.1007/s00170-0168618-0

Senthil Kumar, G. ., Natarajan, U. ., Veerarajan, T. ., \& Ananthan, S. S. . (2014). Quality level assessment for imperfections in GMAW. Welding Journal, 93(3), 85s-97s. Retrieved from

https://www.scopus.com/inward/record.uri?eid= 2-s2.0-

$84896272690 \&$ partnerID $=40 \& m d 5=469 \mathrm{~d} 1 \mathrm{cc} 80$ 105d887ce947d3642828ea2

Shao, Y., Wang, Z., \& Zhang, Y. (2011). Monitoring of liquid droplets in laser-enhanced GMAW. International Journal of Advanced Manufacturing Technology, 57(1-4), 203-214. http://doi.org/10.1007/s00170-011-3266-X

Shen, H. Y., Wu, J., Lin, T., \& Chen, S. B. (2008). Arc welding robot system with seam tracking and weld pool control based on passive vision. International Journal of Advanced Manufacturing Technology, 39(7-8), 669-678. http://doi.org/10.1007/s00170-0071257-8

Shengqiang, F., Hiroyuki, O., Hidennori, T., Yuichi, K., \& Shengsun, H. (2011). Qualitative and quantitative analysis of GMAW welding fault based on Mahalanobis distance. International Journal of Precision Engineering and Manufacturing. http://doi.org/10.1007/s12541011-0127-3

Squillace, A., Prisco, U., Ciliberto, S., \& Astarita, A. (2012). Effect of welding parameters on morphology and mechanical properties of $\mathrm{Ti}$ $6 \mathrm{Al}-4 \mathrm{~V}$ laser beam welded butt joints. Journal of Materials Processing Technology, 212(2), 427-436. http://doi.org/10.1016/j.jmatprotec.2011.10.005

Sreedhar, U., Krishnamurthy, C. V., Balasubramaniam, K., Raghupathy, V. D., \& Ravisankar, S. (2012). Automatic defect identification using thermal image analysis for online weld quality monitoring. Journal of Materials Processing Technology, 212(7), 1557-1566.

http://doi.org/10.1016/j.jmatprotec.2012.03.002

Sreeraj, P., Kannan, T., \& Maji, S. (2013). Estimation of Optimum Dilution in the GMAW 
Process Using Integrated ANN-GA. Journal of Engineering (United States), 2013. http://doi.org/10.1155/2013/285030

Ummenhofer, T., \& Medgenberg, J. (2009). On the use of infrared thermography for the analysis of fatigue damage processes in welded joints. International Journal of Fatigue, 31(1), 130137. http://doi.org/10.1016/j.ijfatigue.2008.04.005

Wang, X., Shi, Y., Yu, G., Liang, B., \& Li, Y. (2016). Groove-center detection in gas metal arc welding using a template-matching method. The International Journal of Advanced Manufacturing Technology, 86(9-12), 27912801. http://doi.org/10.1007/s00170-016-83897

Wang, Z. Z., Ma, X. J., \& Zhang, Y. M. (2011). Simultaneous Imaging and Measurement of Pool Surface and Metal Transfer. Welding Journal, 90(6), 121S-128S.

Wang, Z., Zhang, Y. M., \& Wu, L. (2010). Measurement and Estimation of Weld Pool Surface Depth and Weld Penetration. Welding Journal, 89(6), 117s-126s. Retrieved from https://app.aws.org/wj/supplement/wj0610117.pdf

Wang, Z. (2016). A laser back-lighting based metal transfer monitoring system for robotic gas metal arc welding. Robotics and Computer-Integrated Manufacturing, 38, 52-66. http://doi.org/10.1016/j.rcim.2015.10.004

Wang, Z., Huang, Y., \& Zhang, Y. (2013). Unsupervised droplet identification during the pulsed laser enhanced GMAW process. International Journal of Advanced Manufacturing Technology, 67(5-8), 14491457. http://doi.org/10.1007/s00170-012-45807

Xu, Y., Fang, G., Chen, S., Zou, J. J., \& Ye, Z. (2014). Real-time image processing for visionbased weld seam tracking in robotic GMAW. International Journal of Advanced Manufacturing Technology, 73(9-12), 14131425. http://doi.org/10.1007/s00170-014-59251

Xu, Y., Fang, G., Lv, N., Chen, S., \& Jia Zou, J. (2015). Computer vision technology for seam tracking in robotic GTAW and GMAW. Robotics and Computer-Integrated $\begin{array}{ll}\text { Manufacturing, } & 32,\end{array}$ http://doi.org/10.1016/j.rcim.2014.09.002 